\title{
Laparoscopic Splenectomy: Comparison Between Anterior and Lateral Approaches
}

\author{
Guillaume Podevin, MD, PhD, Anaïs Victor, MD, ${ }^{2}$ Stephan De Napoli, MD, \\ Yves Heloury, MD, $\mathrm{PhD},{ }^{3}$ and Marc David Leclair, MD, $\mathrm{PhD}^{2}$
}

\begin{abstract}
Aim: Splenectomy, except for a traumatic purpose, is now performed through a laparoscopic approach. There are mainly two ways for laparoscopic total or partial splenectomies. For the classic anterior dissection of the splenic vessels, patient is placed in supine position and five ports are required to elevate the spleen and proceed to vessel divisions. With a lateral approach of the pedicle, patient is placed in lateral decubitus position and three ports are sufficient, because gravity help to provide traction on the splenic ligaments and to present hilar vessels and pancreas tail. The aim of our study was to compare surgical complications of those two approaches of laparoscopic splenectomy in children.

Methods: We reviewed 84 medical records of patient operated on for hematological disease between January 1993 and December 2009.

Results: There were 47 anterior and 37 lateral approaches. Sex, disease, median age, operative time, blood lost or hospital stay, and associated laparotomy were not different between the two groups. Operative complications included hemorrhage (5), bowel injury (1), diaphragmatic wound (1), pancreas tail section (1), and parietal hematoma (1) in the anterior group (9 cases) versus 1 hemorrhage in the lateral group $(P<.02)$. There were five laparotomies owing to surgical complications in the anterior group, and none in the lateral group.

Conclusion: Splenectomy through laparoscopic approach is an effective technique. Lateral dissection of the vessels provides less operative complications in children.
\end{abstract}

\section{Introduction}

Towadays, Laparoscopy is the standard approach to 1 perform splenectomy in children. ${ }^{1,2}$ except for a traumatic purpose. Since the first description in 1992 for adults ${ }^{3}$ and in 1993 for children, ${ }^{4}$ most teams used to expose the splenic blood supply via an anterior way, the patient positioned supine. That way required five ports to elevate the spleen and proceed to vessel divisions, for either total or partial splenectomies. In 1994, Park et al. ${ }^{5}$ reported their first experience using a fourport lateral approach in 4 adults. Patient were placed in lateral decubitus position, and because the spleen fell down after the division of posterior splenic ligaments, that approach allowed better exposure of the posterior aspect of hilar vessels and consequently facilitated dissection with a reduced blood loss. The lateral approach was introduced in pediatric surgery in $1996,{ }^{6}$ but to date, there is no study comparing surgical complications of those two ways in children.

\section{Materials and Methods}

We retrospectively reviewed 84 medical records of patient referred in pediatric surgery between January 1993 and December 2009 to perform laparoscopic splenectomy for hematological disorders. Data collected included operative time, blood loss, operative complications, associated laparotomy, postoperative morbidity, and postoperative length of stay. Each of the three surgeons involved in that study had more than 10 years of experience as pediatric surgeons when they started laparoscopic splenectomy and were used to perform other advanced laparoscopic surgical techniques.

The surgical procedures are briefly described as follows. For the anterior approach, the patient was placed in supine position. We used five ports: a $10-\mathrm{mm}$ umbilical port for the scope, a 15-mm port in a left lower quadrant for introduction of the linear stapler or the endo-bag, and three other 5-mm

\footnotetext{
${ }^{1}$ University Hospital, Angers, France.

${ }^{2}$ University Hospital, Nantes, France.

${ }^{3}$ Monash Medical Center, Melbourne, Australia.
} 
ports spread around the costal margin. After opening the gastrocolic ligament and accessing the lesser sac, the short gastric vessels were divided. The splenic pedicle was dissected, with division of pancreatic branches. The splenic artery was divided first with linear stapler or more recently with harmonic scapel. The splenic vein was then divided with the stapler. Finally, colosplenic and splenodiaphragmatic ligaments were cut to mobilize the spleen, which could then be introduced into the endo-bag. Accessory spleens identified in the hilum or omentum were systematically removed. Specimen was exteriorized through the left inferior incision after kelly fragmentation in the bag for most cases, or through pfannenstiel laparotomy if the spleen was too large (more than $15 \mathrm{~cm}$ length). No drainage was usually left in the peritoneal cavity.

For the lateral approach, the patient was positioned in complete lateral decubitus position. A flank cushion was placed under the right side to enlarge the space between the left subcostal margin and iliac crest. The initial 10-mm port was placed at the left subcostal midclavicular line, via an open approach, for the $30^{\circ}$ laparoscope. Two additional ports were placed: a $5-\mathrm{mm}$ port in the epigastrium and a $12-\mathrm{mm}$ port to accommodate the stapler and the endo-bag in the left flank, or more inferiorly in the left lower quadrant for larger spleen. After mobilization of the colonic splenic flexure, the dissection began at the lower pole of the spleen, using the harmonic scalpel. The posterior splenophrenic attachment was divided, allowing the spleen to roll away from the lateral abdominal wall and thus exposing the splenic hilum (Fig. 1). Dissection and division of splenic vessels was then easily carried out using either linear stapler or harmonic scapel with the tool according to the size of the vessels, following by division of short gastric vessels. Spleen extraction followed the same procedure than in anterior approach.

Statistical analysis was carried out using Qi2 test to compare qualitative data and Student $t$-test for quantitative data. There is no need of IRB approval concerning retrospective studies in France.

\section{Results}

Laparoscopic splenectomies were performed through anterior approach in 47 cases up to 2000 and through lateral approach in 37 cases from 2001. There were 38 girls and 48 boys. Median age was 10 (3-23). Indications were hereditary spherocytosis (57 patients), idiopathic thrombocytopenic purpura (16), lymphomas (4), sickle-cell disease (3), and miscellaneous (4). Sex, median age, and disease were not significantly (NS) different between the two groups. Splenectomies were total, except for 6 patients from the lateral group who had partial splenectomy. Associated cholecystectomy was performed in $9(19.1 \%)$ patients from anterior group and $10(27 \%)$ patients from lateral group (NS). Laparotomy for specimen extraction due to large spleen was performed in 13 patients $(27.6 \%)$ from anterior group and $11(29.7 \%)$ from lateral group (NS). Median operative time, blood lost, and postoperative length of stay were no different between the two groups (Table 1). None of the patients required blood product transfusion during or after procedures.

Operative complications included hemorrhages (5), bowel injury (1), diaphragmatic wound (1), pancreas tail section (1), and parietal hematoma (1) in the anterior group ( 9 cases) versus 1 hemorrhage in the lateral group $(P<.02)$. There were five laparotomies owing to surgical complications in the anterior
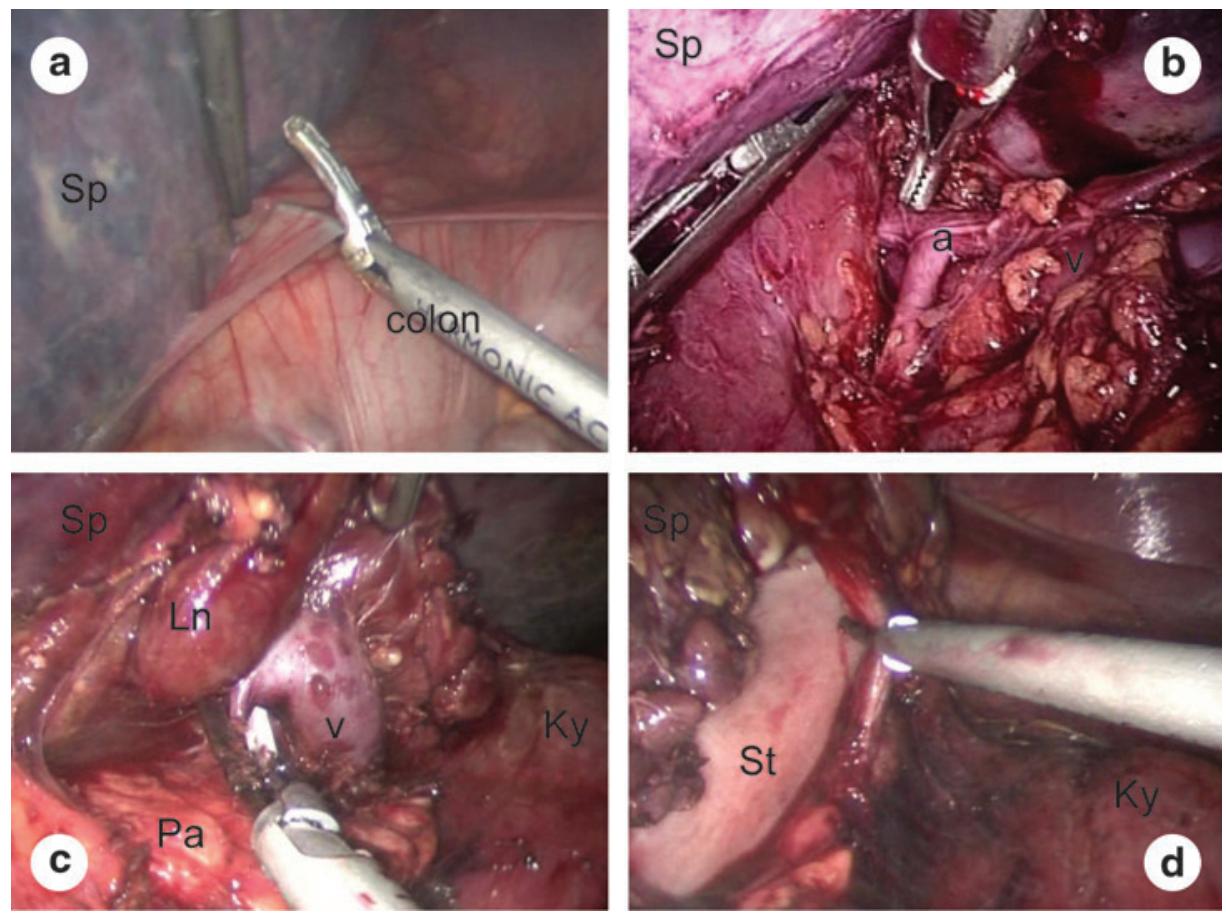

FIG. 1. Laparoscopic splenectomy through a lateral approach. (a) Division of the splenorenal ligament. (b) Dissection of the splenic artery. (c) Dissection of the splenic vein with division of a pancreatic branch. (d) Division of short gastric vessels. a, splenic artery; Ln, lymph node; Ky, kidney; Pa, pancreas; Sp, spleen; St, stomach; v, splenic vein. 
Table 1. Comparison of Operative and Postoperative Data Between Anterior and Lateral Approach

\begin{tabular}{lccc}
\hline & $\begin{array}{c}\text { Anterior } \\
\text { approach }\end{array}$ & $\begin{array}{c}\text { Lateral } \\
\text { approach }\end{array}$ & Signification \\
\hline $\begin{array}{l}\text { Patients } \\
\begin{array}{l}\text { Operative time } \\
\text { (minutes) }\end{array}\end{array}$ & 47 & 37 & - \\
$\begin{array}{l}\text { Operative } \\
\text { complications }\end{array}$ & $9(19.1 \%)$ & $1(2.7 \%)$ & $<.02$ \\
$\begin{array}{l}\text { Conversions } \\
\text { Blood lost (mL) }\end{array}$ & $55(10.6 \%)$ & 0 & NS \\
$\begin{array}{l}\text { Postoperative } \\
\text { morbidity }\end{array}$ & $3(6.3 \%)$ & $30(0-450)$ & NS \\
$\begin{array}{l}\text { Postoperative length } \\
\text { of stay (days) }\end{array}$ & $4(1-15)$ & $4(2-1 \%)$ & NS \\
\hline
\end{tabular}

NS, no statistical difference.

group: four for hemostasis control and one for bowel resection. The fifth hemorrhage in the anterior group and the one in the lateral group had been controlled during the laparoscopic procedure. The difference between the two groups for the number of conversion to laparotomy for surgical complication reached the statistical signification (Table 1).

Postoperative morbidity included phrenic abscess (1), pleural effusion (1), and pulmonary infection (1) for the anterior group (3 cases), and fever after partial splenectomy (2) and pleural effusion (1) for the lateral group (3 cases; NS).

\section{Discussion}

According to the recent clinical practice guidelines of the European Association for Endoscopic Surgery, "Laparoscopic splenectomy may be performed using a lateral, semilateral, or supine approach depending on surgeon preference, spleen size, patient characteristics, and need of concomitant procedures. ${ }^{7 \prime}$ In other words, there is to date no randomized comparison between the supine and lateral approach to assess the best patient position to perform laparoscopic splenectomy. Such study would indeed require standard procedures with definition of surgical steps, vascular control tools, and surgical options according to spleen size, and such study should probably be multicentric concerning the pediatric surgery field, owing to scarce indication in children.

We conducted that retrospective study with all reservations required about such noncontrolled studies for interpretation of the results. In particular, an historical bias between the two groups in the data could have effects on subsequent interpretation. Nevertheless, all 3 surgeons who performed splenectomies in our series were well trained for laparoscopic procedure, and our work showed significant differences in terms of operative complications (9 versus 1 ) in support to lateral approach in children. As other teams in adult surgery, ${ }^{8,9}$ those results confirmed our feeling of better exposure and safer vascular dissection through that approach. The help of gravity allowed for surgeons to not depend on assistants for exposure and to have their two hands free for the whole procedure. There was no difficulty to dissect the ligament structures or the tail of the pancreas from the dorsal splenic vessels, as well as to find accessory spleens, in opposition to anterior approach. ${ }^{10}$ Furthermore, the use of only three ports reduced the postoperative abdominal wall pain and improved cosmetic results. We can expect that new singleport access techniques will still improve cosmetic results. Reports of such technique for splenectomy are few in literature, with only 17 published adult cases in an august 2010 review $^{11}$ and 11 cases in children. ${ }^{12-14}$ The lateral approach with the help of gravity would have the same advantages than with our conventional three-port laparoscopy.

The supine position is indicated if concurrent procedures such as cholecystectomy need to be performed. In that situation, we used to apply the hemi- (or semi-) lateral positioning, described initially by Delaitre et al., ${ }^{15}$ and we adjusted the patient's position by tilting the table so that a fully supine or fully lateral positioning is obtained during the different steps of the procedure. That patient semi-lateral positioning was also required when preoperative ultrasounds were suspected large spleen, expecting extraction difficulties through endo-bag, which could lead to pfannenstiel laparotomy.

In conclusion, with recent technological advances, the laparoscopic approach is considered for many teams the procedure of choice for pediatric splenectomy. ${ }^{16}$ Large series had shown a reasonable rate of complications. ${ }^{17,18}$ In our experience, the right lateral position is safer than the conventional supine approach by providing a more direct view of the splenic hilum.

\section{Disclosure Statement}

No competing financial interests exist.

\section{References}

1. Rescorla FJ, Breitfeld PP, West KW, et al. A case controlled comparison of open and laparoscopic splenectomy in children. Surgery 1998;124:670-675.

2. Minkes RK, Lagzdins M, Langer JC. Laparoscopic versus open splenectomy in children. J Pediatr Surg 2000;35: 699-701.

3. Thibault C, Mamazza J, Létourneau R, et al. Laparoscopic splenectomy: Operative technique and preliminary report. Surg Laparosc Endosc 1992;2:248-253.

4. Tulman S, Holocomb GW, Karamanoukian HL, et al. Pediatric laparoscopic splenectomy. J Pediatr Surg 1993;28:689-692.

5. Park A, Gagner M, Pomp A. The lateral approach to laparoscopic splenectomy. Am J of Surg 1997;173:126-130.

6. Fitzgerald PG, Langer JC, Cameron BH, et al. Pediatric laparoscopic splenectomy using the lateral approach. Surg Endosc 1996;10:859-861.

7. Habermalz B, Sauerland S, Decker G, et al. Laparoscopic splenectomy: The clinical practice guidelines of the European Association for Endoscopic Surgery (EAES). Surg Endosc 2008;22:821-848.

8. Gossot D, Fritsch S, Célérier M. Laparoscopic splenectomy. Optimal vascular control using the lateral approach and ultrasonic dissection. Surg Endosc 1999;13:21-25.

9. Tan M, Zheng C, Wu Z, et al. laparoscopic splenectomy: The latest technical evaluation. World J Gastroenterol 2003;9: 1086-1089.

10. De Lagausie $\mathrm{P}$, Bonnard A, Benkerrou $\mathrm{M}$, et al. pediatric laparosocopic splenectomy: Benefits of the anterior approach. Surg Endosc 2004;18:80-82.

11. Targarona EM, Lima MB, Balague C, Trias M. Single-port splenectomy: Current update and controversies. J Minim Access Surg 2011;7:61-64. 
12. Ponsky TA, Diluciano J, Chwals W, Parry R, Boulanger S. Early experience with single-port laparoscopic surgery in children. J Laparoendosc Adv Surg Tech A 2009;19:551-553.

13. Dutta S. Early experience with single incision laparoscopic surgery: Eliminating the scar from abdominal operations. J Pediatr Surg 2009;44:1741-1745.

14. Garey CL, Laituri CA, Ostlie DJ, Snyder CL, Andrews WS, Holcomb GW 3rd, St Peter SD. Single-incision laparoscopic surgery in children: Initial single-center experience. J Pediatr Surg 2011;46:904-907.

15. Delaitre B, Bonnichon P, Barthes T, et al. Laparoscopic splenectomy. The "hanging spleen technique" in a series of nineteen cases. Ann Chir 1995;49:471-476.

16. Danielson PD, Shaul DB, Phillips JD, et al. Technical advances in pediatric laparoscopy have had a beneficial impact on splenectomy J Pediatr Surg 2000;35:15781581.
17. Rescorla FJ, West KW, Engum SA, et al. Laparoscopic splenic procedures in children: Experience in 231 children. Ann Surg 2007;246:683-688.

18. Murawski M, Patkowski D, Korlacki W, et al. Laparoscopic splenectomy in children- a multicentric experience. J Ped Surg 2008;43:951-954.

Address correspondence to: Guillaume Podevin, MD, PhD Service de Chirurgie Infantile Batiment Robert Debré-CHU

4 rue Larrey Angers 49933

France

E-mail: gupodevin@chu-angers.fr 